OPEN ACCESS

Edited by:

Bruno Bastide,

Lille University of Science and

Technology, France

Reviewed by:

Steve Lancel,

Université de Lille, France

Andreas Pfeiffer,

Charité Medical University of Berlin,

Germany

${ }^{*}$ Correspondence: Hongshuai Li hol24@pitt.edu

Specialty section: This article was submitted to Striated Muscle Physiology, a section of the journal

Frontiers in Physiology

Received: 02 November 2020 Accepted: 16 February 2021

Published: 08 March 2021

Citation:

Sun H, Sherrier M and Li H (2021)

Skeletal Muscle and

Bone - Emerging Targets of

Fibroblast Growth Factor-21.

Front. Physiol. 12:625287.

doi: 10.3389/fphys.2021.625287

\section{Skeletal Muscle and Bone - Emerging Targets of Fibroblast Growth Factor-21}

\author{
Hui Sun ${ }^{1,2}$, Matthew Sherrier ${ }^{1,3}$ and Hongshuai $L i^{1 *}$ \\ ${ }^{1}$ Musculoskeletal Growth \& Regeneration Laboratory, Department of Orthopaedic Surgery, University of Pittsburgh, \\ Pittsburgh, PA, United States, 'Department of Orthopaedic Surgery, Shanghai Jiao Tong University Affiliated Sixth People's \\ Hospital, Shanghai, China, ${ }^{3}$ Department of Physical Medicine and Rehabilitation, University of Pittsburgh Medical Center, \\ Pittsburgh, PA, United States
}

Fibroblast growth factor 21 (FGF21) is an atypical member of the FGF family, which functions as a powerful endocrine and paracrine regulator of glucose and lipid metabolism. In addition to liver and adipose tissue, recent studies have shown that FGF21 can also be produced in skeletal muscle. As the most abundant tissue in the human body, skeletal muscle has become increasingly recognized as a major site of metabolic activity and an important modulator of systemic metabolic homeostasis. The function and mechanism of action of muscle-derived FGF21 have recently gained attention due to the findings of considerably increased expression and secretion of FGF21 from skeletal muscle under certain pathological conditions. Recent reports regarding the ectopic expression of FGF21 from skeletal muscle and its potential effects on the musculoskeletal system unfolds a new chapter in the story of FGF21. In this review, we summarize the current knowledge base of muscle-derived FGF21 and the possible functions of FGF21 on homeostasis of the musculoskeletal system with a focus on skeletal muscle and bone.

Keywords: skeletal muscle, fibroblast growth factor 21, bone, myokine, expression, muscular dystrophy, Osteoporosis

\section{INTRODUCTION}

The fibroblast growth factor (FGF) family is a group of 22 related proteins grouped into six subfamilies, based on genetic and functional similarities, that have a wide variety of functions (Degirolamo et al., 2016). FGF21, together with FGF19 (human ortholog of mouse FGF15) and FGF23, belongs to the FGF19 subfamily, which represents an atypical group of FGFs due to the lack of affinity for heparin sulfates that allows them to act in an endocrine manner to influence the enterohepatic circulation of bile, regulate glucose and lipid metabolism, and maintain phosphorus and calcium homeostasis (Dolegowska et al., 2019). FGF15/19 is produced in the liver in response to the postprandial release of bile acids (Struik et al., 2019), fat-soluble vitamins A and D, and cholesterol (Schmidt et al., 2010; Henkel et al., 2011) and primarily functions as a negative feedback mechanism to decrease bile acid synthesis (Holt et al., 2003). In addition to controlling the enterohepatic circulation of bile acid, FGF15/19 also regulates systemic lipid and glucose metabolism via its action on the liver, adipose tissue, and central nervous system (Owen et al., 2015; Izaguirre et al., 2017). FGF23 is mainly produced in osteocytes and functions as an important regulator of phosphate and 
calcium metabolism through multiple organs, especially the kidney (Edmonston and Wolf, 2020). FGF21 is primarily produced by the liver and adipose tissue in response to various metabolic, oxidative, nutritional, hormonal, or environmental stimuli, which provides signaling to multiple tissues including the central nervous system (Bookout et al., 2013) and adipose tissue (Canto and Auwerx, 2012) to mediate carbohydrate and lipid metabolism (Kim and Lee, 2014; Markan et al., 2014).

Fibroblast growth factor 21 functions not only as a regulator of energy metabolism, but also as a stress hormone for maintenance of tissue homeostasis in an autocrine, paracrine, or endocrine fashion (Kim and Lee, 2014; Salminen et al., 2017a). Along these lines, FGF21 expression is induced by the integrated stress response (ISR) pathway, an evolutionarily conserved adaptive system of eukaryotic cells for the restoration of cellular homeostasis in response to diverse stimuli including aging, obesity, and nutritional stressors (Salminen et al., 2017a). The cellular context in addition to the character and intensity of the stressful precipitant dictate the outcome of the ISR (Pakos-Zebrucka et al., 2016). As such, the beneficial or detrimental effects of FGF21 are dependent on an integration of variables, making this unique and controversial hormone functional therapeutically and as a biomarker of disease (Oost et al., 2020). Although complex in its function and regulation, the current integrative physiological role of FGF21 is as a key regulator in the adaptation to stress that can limit the progression of metabolic disease states with the goal of restoring homeostasis (Kim and Lee, 2014).

In addition to the hepatic and adipose production, recent studies have demonstrated that FGF21 can be expressed and secreted from other peripheral tissues, such as skeletal muscle (Keipert et al., 2014; Fisher and Maratos-Flier, 2016; Lehtonen et al., 2016; Tezze et al., 2019), thymus (Youm et al., 2016), and pancreas (Nishimura et al., 2000; Fisher and MaratosFlier, 2016). In humans, skeletal muscle is the most abundant tissue in the body, accounting for more than $40 \%$ of body weight in healthy individuals (Wang and Pessin, 2013), and has become increasingly recognized as a major site of metabolic activity and an important modulator of systemic metabolic homeostasis (Tezze et al., 2017). Growing evidence suggests that muscle-derived growth factors or cytokines, known as myokines (Pedersen and Febbraio, 2012), may be responsible for the endocrine effects (Demontis et al., 2013). The function and mechanisms of action of musclederived FGF21 have drawn attention due to the findings of considerable amounts of FGF21 expressed and secreted under certain pathologic conditions (Lehtonen et al., 2016). Despite recent publications on muscle-derived FGF21 and its effect on the musculoskeletal system, significant knowledge gaps exist. The purpose of this review is to summarize the current knowledge base of muscle-derived FGF21 and the possible functions of FGF21 on homeostasis of the musculoskeletal system with a focus on skeletal muscle and bone. Knowledge of the ectopic expression of FGF21 from skeletal muscle and its potential effects on the musculoskeletal system has provided new avenues of investigation into the relevance of FGF21 to health and disease.

\section{FGF21 AS A MYOKINE}

Myokines are cytokines or peptides synthesized and released by muscle in response to muscular contraction or various stimuli (Pedersen et al., 2007). Under basal conditions, the expression of FGF21 is predominantly from liver and adipose tissue (Nishimura et al., 2000), however, the expression and secretion of FGF21 from skeletal muscle is significantly increased under certain conditions, such as mitochondrial dysfunction (Keipert et al., 2014; Lehtonen et al., 2016; Steele et al., 2016; Khan et al., 2017; Romanello et al., 2019), muscular dystrophy (Lovadi et al., 2017; Zhou et al., 2018; Li et al., 2020), and exercise (Ost et al., 2016; Kruse et al., 2017; Morville et al., 2018). Thus, in addition to being a hepatokine and adipokine, FGF21 is also well-established as a myokine (Pedersen and Febbraio, 2012; Itoh, 2014; Pereira et al., 2017). In this section, we will discuss the current knowledge base regarding the identification of muscle-derived FGF21 and the mechanisms that drive its expression from skeletal muscle.

\section{Mitochondrial Disorders}

Fibroblast growth factor 21 is induced in and secreted from skeletal muscle in mitochondrial myopathies and insults of various stresses in skeletal muscle. Increased levels of FGF21 in the skeletal muscle and serum have been demonstrated in mouse models of familial progressive external ophthalmoplegia, a progressive adult-onset mitochondrial respiratory chain deficiency (Badenhorst et al., 2015), skeletal muscle-specific ablation of autophage-related 7 (Kim et al., 2013a), and skeletal muscle specific optic atrophy 1 (OPA1, a mitochondrial fusion protein) deficiency (Pereira et al., 2017; Tezze et al., 2017; Rodriguez-Nuevo et al., 2018), all of which result in mitochondrial dysfunction. Additionally, overexpression of uncoupling protein 1 (UCP-1), a key regulatory molecule of mitochondrial function results in the ectopic expression of FGF21 from skeletal muscle (Keipert et al., 2014). Impaired mitochondrial fat oxidation has also been demonstrated to induce the expression of FGF21 in skeletal muscle. The transgenic overexpression of perilipin 5 (a lipid droplet protein), which can increase lipid storage in the muscle and in turn affect its utilization as an energy source by skeletal muscle, stimulates the expression of FGF21 from skeletal muscle (Harris et al., 2015). Inversely, perilipin 5 deletion increases fatty acid oxidation and decreases FGF21 production by muscle (Montgomery et al., 2018). Skeletal muscle-specific deletion of carnitine palmitoyltransferase-1b, which transports long-chain fatty acid into mitochondria for beta-oxidation, also induces FGF21 expression from muscle (Vandanmagsar et al., 2016).

In humans, serum FGF21 levels are significantly increased in patients with primary muscle-manifesting respiratory chain deficiencies, particularly those caused by pathogenic mutations in mitochondrial DNA (Suomalainen et al., 2011; Crooks et al., 2014) with the muscle believed to be the primary contributory organ to circulating levels (Crooks et al., 2014). Thus, FGF21 has recently gained attention as a potential 
biomarker of mitochondrial diseases (Tyynismaa et al., 2010; Suomalainen et al., 2011; Lehtonen et al., 2016, 2020) and could represent a potential target for the treatment of mitochondrial myopathies and muscle mitochondria dysfunction.

\section{Muscular Dystrophy and Muscle Regeneration}

Elevated serum FGF21 has been demonstrated in animal models of Duchenne muscular dystrophy (DMD; Zhou et al., 2018; Li et al., 2020) and is primarily derived from dystrophic muscle (Li et al., 2020). However, the mechanisms that drive the expression of FGF21 from dystrophic skeletal muscle is still largely unknown. Mitochondrial deficiency (Timpani et al., 2015), autophage dysfunction (De Palma et al., 2012), and endoplasmic reticulum (ER) stressors (Pauly et al., 2017) have been implicated as part of the pathogenesis of DMD and have also been shown to increase the expression of FGF21 from skeletal muscle (Zhou et al., 2018; Li et al., 2020). Furthermore, one of the hallmarks of DMD pathology is constant muscle degeneration and regeneration (Rosenberg et al., 2015). Interestingly, FGF21 expression has been detected in C2C12 cells during myogenic differentiation, and myoblast determination protein $1(\mathrm{MyoD})$ is implicated as a major controller of FGF21 gene transcription (Ribas et al., 2014). Thus, it is possible that higher expression of FGF21 in DMD may be due to increased myogenic differentiation. Further studies are needed to verify if elevated FGF21 is also present in human patients, to elucidate the mechanism behind the increased FGF21 from dystrophic muscle, and to determine whether downregulation of FGF21 is accompanied by an improved muscle function.

\section{Exercise}

Multiple studies have shown that FGF21 is associated with exercise, however, the literature regarding the exercise-induced changes in FGF21 in the serum, liver, and skeletal muscle is inconsistent and contradictory. With regards to the serum levels, studies in mice and humans have shown an exerciseinduced increase (Cuevas-Ramos et al., 2012; Kim et al., 2013b), decrease (Yang et al., 2011; Taniguchi et al., 2016; Shabkhiz et al., 2020), or no change in circulating FGF21 (Andersen et al., 2014; Besse-Patin et al., 2014). Additionally, the data regarding the impact of liver-derived FGF21 during exercise are contradictory. Hansen et al. $(2015,2016)$ have shown an induction of hepatic FGF21 synthesis in response to exercise through the ATF4/PPAR $\alpha$ mediated pathway, glucagon to insulin ratio, and free fatty acid levels. Furthermore, acute and longterm endurance exercise at intensities between 50 and $80 \%$ VO2max in humans results in elevated serum levels of FGF21 via increased hepatic expression of FGF21 but without increased expression in skeletal muscle or adipose tissue (Cuevas-Ramos et al., 2012). Similarly, a mouse study has shown an exerciseinduced increase in hepatic FGF21 expression (Berglund et al., 2011). However, other studies have shown no increase in hepatic FGF21 after exercise (Fletcher et al., 2016; Loyd et al., 2016). It is important to note that there are significant methodological issues that likely account for the inconsistencies. Firstly, the mice and humans studied were in various metabolic states, including exercise-trained vs. untrained, type 2 diabetes mellitus, obesity, and advanced age. Secondly, exercise protocols were not comparable with variations in the types, intensities, and duration of exercise. Finally, FGF21 expression could also be affected by the participant's diet and circadian rhythm (Yu et al., 2011) in addition to the interspecies variability (Staiger et al., 2017; Keuper et al., 2020). Future studies should address and control for these important confounding variables.

Recent studies have raised the question of how significant the contribution of exercise-induced skeletal muscle-derived FGF21 is to bioactive and circulatory levels. Previous studies demonstrated that resistance training and higher intensity exercise increases FGF21 expression in skeletal muscle (Tanimura et al., 2016; Sabaratnam et al., 2018), although to a lesser extent than the increase in hepatic expression. However, recent reports have challenged this notion. Parmar et al. (2018) demonstrated no change in skeletal muscle-derived FGF21 between baseline and $48 \mathrm{~h}$ following a single-leg maximal eccentric contraction exercise. Additionally, moderate-intensity continuous training has been recently shown to produce higher expression of FGF21 and $\beta$-klotho expression in the liver and muscle of the obese mice than high-intensity interval training (Xiong et al., 2020). As mentioned, the contradictory data and inconsistencies in the literature can be attributed to variation in study design and outcome measures. The source of FGF21 during exercise is likely dependent on the individual training level (i.e., athlete vs. untrained), intensity, type, and duration of the exercises along with the time points at which blood samples are collected. More studies are needed to understand how and to what degree exercise affects the expression of FGF21 from the liver and skeletal muscle. Overall, it is commonly recognized that the exercise influences the systemic, hepatic, and skeletal musclederived FGF21, although the mechanism remains unknown.

\section{Aging}

Although early studies implicated FGF21 as a pro-longevity factor, recent research has questioned that notion. Extended lifespan has been observed in a transgenic mouse line, which expressed the FGF21 gene (Tg-FGF21) from liver under the control of an ApoE promoter (Inagaki et al., 2008; Zhang et al., 2012). There are also indications that hepatic overexpression of FGF21 can protect against age-related immune senescence (Youm et al., 2016). Youm et al. (2016) observed that thymic involution, a common hallmark of aging, was significantly delayed in Tg-FGF21 mice. FGF21 possesses many mechanistic properties that may impact the aging process. FGF21 stimulates adenosine monophosphate-activated protein kinase (AMPK) signaling (Chau et al., 2010; Salminen et al., 2017c), an established pro-longevity pathway, both directly through the FGFR1/klotho complex and indirectly via induction of adiponectin expression (Lin et al., 2013; Hui et al., 2016). FGF21 can also facilitate crosstalk among hormonal systems such as the somatotropic axis and the hypothalamic-pituitaryadrenal pathway (Salminen et al., 2017b). Additionally, FGF21 has been proposed to regulate longevity through its ability 
to promote interactions between energy metabolism and stress responses (Salminen et al., 2017a,b).

Despite the aforementioned beneficial effects observed in experimental animal models, the notion that FGF21 is a pro-longevity factor has been challenged in the literature. Studies indicate that circulating levels of FGF21 are elevated in several metabolic diseases, such as obesity, type 2 diabetes, and fatty liver disease (Zhang et al., 2008; Liu et al., 2015). FGF21 has been shown to increase with age among healthy individuals independent of body composition, e.g., fat percent and body mass index (Hanks et al., 2015). Interestingly, a recent study has found that circulating levels of FGF21 are associated with worsened health parameters and mortality in the elderly (Conte et al., 2018). In these contexts, whether FGF21 is beneficial or detrimental is still debated. Moreover, the source organ or tissue of elevated circulating FGF21 during aging is still unclear.

It remains unknown what role skeletal muscle-derived FGF21 plays in its potential health and life extension effects. Skeletal muscle has been emerging as an important mediator of systemic metabolic homeostasis (Baskin et al., 2015) and myokines are likely, in part, responsible for the modulation of aging physiology (Demontis et al., 2013). There is mounting evidence indicating that the elevated FGF21 expression from skeletal muscle under a variety of stresses can regulate whole-body metabolism as evidenced by preventing diet-induced obesity and insulin resistance (Kim et al., 2013a; Jung et al., 2015; Pereira et al., 2017). However, whether this ectopic expression of musclederived FGF21 imparts a beneficial effect on longevity remains unknown. Interestingly, Tezze et al. (2017) reported that the increased expression and secretion of FGF21 from skeletal muscle in a muscle-specific deletion of the OPA1 mouse model appears to be responsible for an accelerated aging phenotype. In this study, increased expression of myokine FGF21 was correlated with a precocious systemic senescence phenotype and premature death, while inhibition of FGF21 greatly ameliorated the aging phenotype (Tezze et al., 2017). Given that pro-longevity effects have mainly been observed in transgenic mice with hepatic FGF21 overexpression (Inagaki et al., 2008; Zhang et al., 2012; Youm et al., 2016), this study highlights the possibility that the longevity effects of FGF21 may be liverspecific. Further studies using tissue-specific over/down the expression of FGF21 are needed to determine whether the longevity effects of FGF21 are origin tissue-specific and to gain mechanistic insights.

\section{Nutrient Stress}

A growing body of literature has demonstrated that nutritional stressors and dietary macronutrient composition resulting in metabolically unhealthy obesity can regulate FGF21 expression and signaling, serving to coordinate and restore metabolic homeostasis. In this section, we highlight fasting and obesity as two ends of the nutritional spectrum with a focus what is known about the role of skeletal muscle-derived FGF21.

Fasting in mice and humans induces expression of hepatic FGF21 via the peroxisome proliferator-activated receptor $\alpha$ (PPAR $\alpha$ ) pathway (Inagaki et al., 2007; Galman et al., 2008). This PPAR $\alpha$-mediated FGF21 induction also increases fatty acid oxidation and ketogenesis in the setting of nutritional ketosis, suggesting that FGF21 functions in the adaptation to fasting or ketosis (Badman et al., 2007). Whereas the induction in FGF21 occurs within $24 \mathrm{~h}$ of fasting in mice (Badman et al., 2007), elevations in FGF21 in humans are not seen in short-term fasting regimens (Galman et al., 2008; Dushay et al., 2010; Fazeli et al., 2015b; Nygaard et al., 2018; Vinales et al., 2019) but only appear after prolonged fasting of at least 7 days (Galman et al., 2008; Fazeli et al., 2015b). The higher metabolic rate of mice as compared with humans has been proposed as an explanation for this discrepancy. With regards to skeletal-muscle derived FGF21, in 24-h fasted WT mice, the levels of FGF21 mRNA were significantly increased (Oost et al., 2019). However, the contribution of FGF21 as a myokine to the adaptive starvation response in mice or humans remains unknown.

Nutrient overload and obesity are also capable of influencing gene expression and circulating levels of FGF21 in mice and humans (Zhang et al., 2008; Fisher et al., 2010). Studies have demonstrated impaired FGF21 signaling in the liver, pancreas, and white adipose tissue of obese mice (Fisher et al., 2010; So et al., 2013), initially suggesting that obesity is an FGF21resistant state. However, the concept of FGF21 resistance remains incompletely understood as a result of the undetermined overlap and differences between the physiological and pharmacological effects of FGF21 in addition to its mechanisms of action on different tissues (Hale et al., 2012; Markan, 2018; Martinez-Garza et al., 2019). The current understanding is that the liver is the primary contributory organ of circulating FGF21 in the setting of metabolically unhealthy obesity with unelucidated impact of FGF21 as a myokine to the systemic milieu (Keuper et al., 2020).

\section{Signaling Pathways That Drive the Expression of FGF21 From Skeletal Muscle}

Different from being canonically produced by the liver and adipose tissue in response to starvation, which is largely controlled by PPAR $\alpha$ (Badman et al., 2007; Lundasen et al., 2007) and PPAR $\gamma$ (Muise et al., 2008; Wang et al., 2008), respectively, the ectopic expression of FGF21 from skeletal muscle is driven by various stress-related signaling pathways (Figure 1). Induction of activating transcription factor 4 (ATF4) as a master regulator of the ISR leads to FGF21 expression (Kim et al., 2013a; Keipert et al., 2014; Harris et al., 2015; Miyake et al., 2016) and appears to be a common link among the ER stress produced in mitochondrial deficiency and impaired autophagy mouse models. In addition, insulin stimulates the expression of FGF21 from skeletal muscle via the Phosphoinositide 3-kinase/Protein kinase B (PI3K/Akt1) signaling pathway (Izumiya et al., 2008; Vandanmagsar et al., 2016). The p38 mitogen-APK (MAPK)/AFT2/MyoD signaling pathway is involved in FGF21 expression during myogenesis (Ribas et al., 2014). AMPK/Akt1 signaling mainly drives FGF21 expression from skeletal muscle when mitochondrial fat oxidation is inhibited (Vandanmagsar et al., 2016). Finally, mammalian target of rapamycin (mTOR) signaling pathways have also been reported to be involved in the regulation of FGF21 expression 


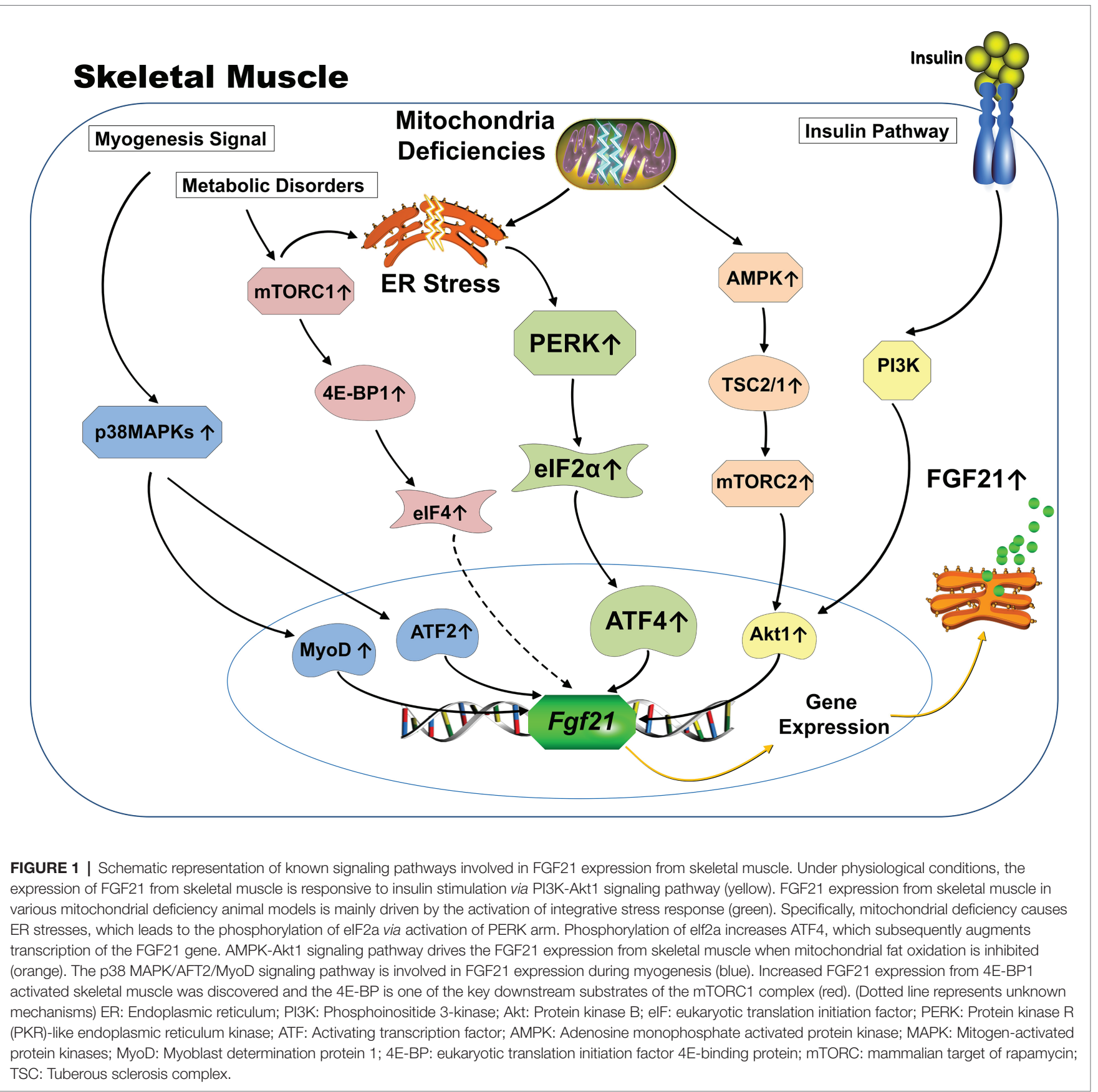

from skeletal muscle. Both activation of mTOR complex 1 (mTORC1; Guridi et al., 2015; Tsai et al., 2015) and mTORC2 (Vandanmagsar et al., 2016) have been reported to induce FGF21 expression from muscle.

\section{THE EFFECTS OF FGF21 ON SKELETAL MUSCLE}

Although skeletal muscle was historically not considered to be a target tissue for FGF21 due to a lack of expression of $\beta$-klotho (Ito et al., 2000; Suzuki et al., 2008), recent studies have confirmed the expression of FGFRs and $\beta$-klotho in skeletal muscle albeit at very low levels (Jeon et al., 2016; Benoit et al., 2017; Tezze et al., 2017), which has opened a new area of research. In this section, we will discuss skeletal muscle as a novel target of FGF21 (Figure 2).

\section{The Expression of FGFRs and $\beta$-Klotho in Skeletal Muscle}

Several studies have confirmed the expression of FGFRs and $\beta$-klotho in the skeletal muscle of both mice and humans (Jeon et al., 2016; Vandanmagsar et al., 2016; Benoit et al., 2017; 


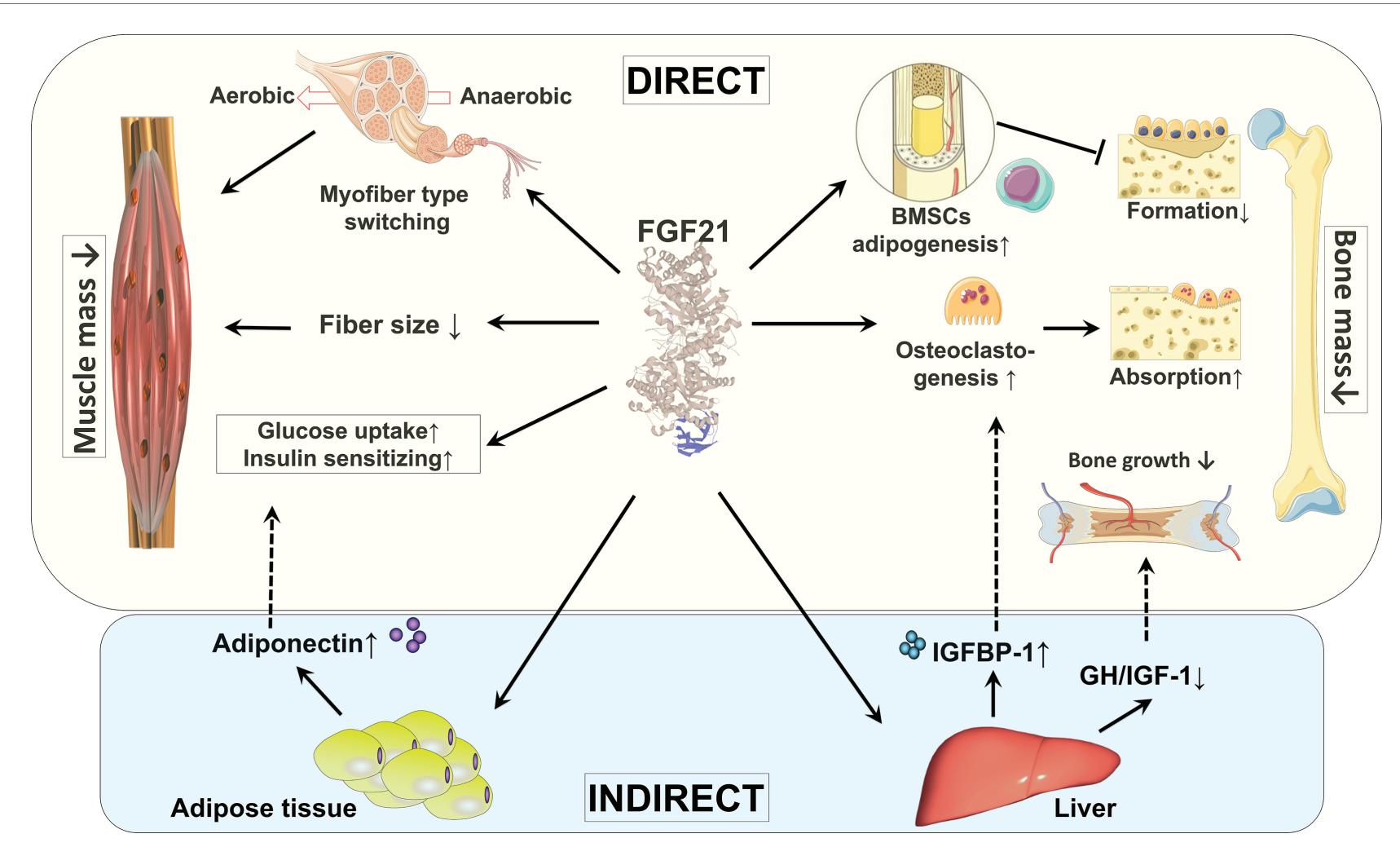

FIGURE 2 | Direct and indirect effects of FGF21 on skeletal muscle and bone. By regulating fiber type distribution and fiber size, skeletal muscle mass might be impacted by FGF21. Under certain pathological conditions, FGF21 is a causative factor of muscle atrophy. The direct effects of FGF21 on skeletal muscle are enhancing glucose uptake and insulin sensitization. FGF21's action on muscle glucose metabolism might also be indirectly mediated by adiponectin secreted from adipose tissue. By stimulation of adipogenesis in BMSCs by FGF21, bone formation is decreased. FGF21 may stimulate bone absorption directly by increasing osteoclastogenesis and indirectly via induction of IGFBP-1. In addition, by blunting the GH/IGF-1 signaling pathway in liver, bone growth is indirectly inhibited by FGF21. BMSCs: bone marrow-derived mesenchymal stem cells; GH/IGF-1: growth hormone/insulin-like growth factor-1; IGFBP-1: IGF-1 binding protein 1.

Tezze et al., 2017) in addition to isolated myotubes in culture (Lee et al., 2012; Jeon et al., 2016). Moreover, although at a very low level compared to liver, $\beta$-klotho expression appears to be dependent on muscle fiber type, with significantly higher expression in soleus muscle (mainly slow oxidative muscle fiber) when compared to the gastrocnemius muscle (mainly fast glycolytic muscle fiber; Jeon et al., 2016).

Expression levels of $\beta$-klotho in muscle correlate with increased circulating FGF21. Lee et al. (2012) demonstrated a time-dependent increase in $\beta$-klotho expression in human skeletal muscle myotubes (HSMMs) after exposure to exogenous FGF21. Significantly elevated expression of $\beta$-klotho in muscle was also observed in a mouse model of mitochondrial fat oxidation impaired with higher induction of FGF21 (Vandanmagsar et al., 2016). Similarly, both FGF21 and $\beta$-klotho are induced in atrophic muscle after acute deletion of the mitochondrial fusion gene Opal (Tezze et al., 2017). Accordingly, the specific inhibition of FGF21 in skeletal muscle is associated with downregulation of $\beta$-klotho (Tezze et al., 2017). Taken together, accumulating evidence demonstrates the coordinated regulation of FGF21 and $\beta$-klotho in skeletal muscle, which suggests their involvement in muscle homeostasis (Oost et al., 2019), although the significance remains unclear.

\section{Does FGF21 Affect Muscle Mass?}

Few studies on FGF21 transgenic overexpression or supraphysiologic FGF21 administration in normal animal models have reported muscle phenotypes (Inagaki et al., 2008; Zhang et al., 2012; Youm et al., 2016), partially due to the early notion that skeletal muscle is an unlikely target tissue for FGF21 (Ito et al., 2000; Suzuki et al., 2008). Moreover, studies have explicitly reported the absence of noticeable signaling responses (FRS2 and ERK1/2 phosphorylation; Fisher et al., 2011) and effects on muscle mass or functionality of adult WT mice after exogenous administration of FGF21 (Benoit et al., 2017).

However, studies based on diseased animal models have suggested that skeletal muscle derived-FGF21 may be involved in the pathogenesis of muscle atrophy. Reduced muscle mass was found in UCP-1 transgenic mice (Keipert et al., 2014), carnitine palmitoyltransferase-1b specific knock-out (KO) in skeletal muscle (Cpt1bm-/-) mice (Vandanmagsar et al., 2016), and global and skeletal muscle conditional Opa-1-/- mice (Tezze et al., 2017), all of which have demonstrated elevated expression of FGF21 from skeletal muscle, as described above. Although marginal, inhibition of the elevated FGF21 expression from skeletal muscle in Opa-1-/- mice, via skeletal musclespecific FGF21 KO, demonstrated beneficial effects on muscle 
mass (Tezze et al., 2017), which suggests that FGF21 might be a causative factor or mediator in the muscle atrophy observed in this mitochondrial deficiency animal model. Additionally, skeletal muscle-conditional FGF21 KO mice were significantly protected from muscle loss and weakness induced by fasting (Oost et al., 2019). Moreover, in vivo FGF21 overexpression from skeletal muscle via direct virus injections induces elevated mitophagy and results in muscle loss (Oost et al., 2019). Taken together, it is plausible that muscle-derived FGF21 plays a permissive role or mediates muscle loss in specific pathological conditions that can cause muscle atrophy. However, whether the increased expression of skeletal musclederived FGF21 is a causative factor of muscle atrophy or an adaptive mechanism is still unclear. Moreover, whether the effects of FGF21 on muscle atrophy is via binding FGFRs and $\beta$-klotho and the downstream signaling mechanisms are still unknown. To answer those questions, additional models of knock-down or $\mathrm{KO}$ of $\beta$-klotho expression in skeletal muscle are needed (Jensen-Cody et al., 2020).

\section{FGF21 in Skeletal Muscle Energy Metabolism}

Fibroblast growth factor 21 is a well-established regulator of carbohydrate and lipid metabolism, which mediates the adaptive starvation response primarily via its action on white and brown adipose tissue and liver (Fisher and Maratos-Flier, 2016; Staiger et al., 2017; Dolegowska et al., 2019). The action of FGF21 on adipocytes results in increased insulin sensitivity, glucose uptake, fatty acid storage, and oxidative capacity (Chau et al., 2010; Staiger et al., 2017; BonDurant and Potthoff, 2018), while its action on liver results in induction of hepatic fatty acid oxidation, ketogenesis, and gluconeogenesis, as well as the suppression of de novo lipogenesis (Fisher and MaratosFlier, 2016; Staiger et al., 2017). The results of FGF21-class molecule pharmacotherapy in mice, non-human primates, and humans have been critically reviewed (Sonoda et al., 2017; BonDurant and Potthoff, 2018) and include decreased body weight, blood glucose levels, insulin, triglycerides, total cholesterol, and total free fatty acids. Given that skeletal muscle is responsible for $70-80 \%$ of insulin-stimulated glucose uptake and a major determinant of glucose and lipid metabolism (Hommelberg et al., 2011; Lee et al., 2012; Bandet et al., 2019), understanding skeletal muscle as a potential target of FGF21 and the role of FGF21 in substrate metabolism remain important, unsolved questions.

The direct effect of FGF21 on skeletal muscle myotubes in enhancing glucose uptake has been demonstrated in several in vitro studies. Mashili et al. (2011) provided evidence that FGF21, though at a supraphysiologic dosage of $1 \mathrm{ug} / \mathrm{ml}$, had a direct effect on enhancing skeletal muscle glucose uptake in cultured HSMMs via increasing mRNA/protein expression of glucose transporter-1 (GLUT1) but not expression or cell surface translocation of GLUT4. Others have found that FGF21 (100 or $200 \mathrm{ng} / \mathrm{ml}$ ) administration increases glucose uptake in palmitate-induced insulin resistant HSMMs (Lee et al., 2012). GLUT1 and GLUT4 loss-of-function data suggest that FGF21 increases glucose uptake in HSMMs via not only GLUT1 but also GLUT4 (Lee et al., 2012). Additionally, studies have reported that in myotubes isolated from a carnitine palmitoyltransferase- $1 \mathrm{~b}$ skeletal muscle conditional KO mouse, FGF21 acts in a paracrine manner to increase basal glucose uptake via GLUT1 (Vandanmagsar et al., 2016). Thus, it appears that FGF21 acts on skeletal muscle to increase glucose uptake via GLUT1 (and possibly GLUT4), at least in supraphysiologic concentrations. The importance of FGF21 on skeletal muscle glucose uptake under physiological conditions is still unknown.

Studies have shown that FGF21 pre-exposure increases insulin-stimulated glucose uptake in isolated mouse soleus and extensor digitorum longus (EDL) muscles, which suggests an insulin-sensitizing effect (Mashili et al., 2011). Others demonstrated that FGF21 treatment restored palmitate-inhibited insulin signaling in HSMMs to improve the insulin sensitivity via phosphorylation of insulin receptor substrate 1 (IRS-1) and Akt (Lee et al., 2012). Furthermore, FGF21 can improve downstream insulin signaling in mouse skeletal muscle tissue via repression $\mathrm{mTORC1}$, leading to subsequent repression of IRS1 phosphorylation at Ser636/639 (Vandanmagsar et al., 2016). Thus, it appears that insulin sensitization represents the primary mechanism underlying the glycemic action of FGF21.

Although several studies have demonstrated that FGF21 can regulate primary myotube glucose uptake in vitro, there is a dearth of research regarding the in vivo bioactivity of FGF21 on skeletal muscle glucose metabolism. FGF21 was found to have no impact on basal glucose uptake in isolated mouse EDL and soleus muscles (Mashili et al., 2011). In leptin-deficient $(o b / o b)$ mice, a bolus injection of FGF21 increased GLUT1 mRNA in white adipose tissue, but not in skeletal muscle, liver, kidney, or brain (Kharitonenkov et al., 2005). Further in vivo studies are needed to validate the importance of circulating FGF21 on skeletal muscle glucose metabolism both in physiologic and pathologic conditions. In addition to its importance in the regulation of glucose metabolism, skeletal muscle also regulates lipid and ketone body metabolism (Lipina and Hundal, 2017; Sherrier and Li, 2019). However, the effects of FGF21 on lipid and ketone body metabolism in skeletal muscles are still largely unknown.

The molecular mechanism(s) of FGF21 on glucose and lipid metabolism in skeletal muscle remain unknown. Whether the effect of FGF21 is mediated via FGFRs/ $\beta$-klotho, and which FGFR(s) play a major role has not been examined. Most studies have used whole muscle lysate for detection of $\beta$-klotho expression. Thus far, no convincing spatial histological studies have demonstrated the expression of $\beta$-klotho at a cellular level in skeletal muscle, which contains multiple cell types in addition to myofibers. Moreover, studies in mice lacking $\beta$-klotho have revealed the possibility of the existence of klothoindependent FGF21 signaling pathways whereas yet undefined co-factors are implicated (Tomiyama et al., 2010). Interestingly, a recent study reported that the metabolic effects on glucose homeostasis and insulin sensitivity of FGF21 were partially abrogated in adiponectin KO mice (Lin et al., 2013). This is exciting as adipocytes are a well-known target of FGF21 and intramuscular adipose tissue (IMAT) has emerged as an important 
player in insulin-resistant associated diseases; high levels of IMAT are associated with insulin resistance and loss of muscle strength (Muoio and Newgard, 2008; Muoio, 2010; Coen and Goodpaster, 2012; Addison et al., 2014). It is reasonable to speculate that this muscle/fat crosstalk via FGF21/adiponectin may play an important role in regulating the energy homeostasis in skeletal muscle. Furthermore, these data highlight the possibility that FGF21's action on muscle metabolism might also be indirectly mediated by other factors.

Skeletal muscle is comprised of different fiber types, the composition and distribution of which is established during embryonic development but later can be modulated by neural and hormonal factors in addition to exercise (Schiaffino and Reggiani, 2011; Yan et al., 2011). Mature skeletal muscle is heterogeneous and composed of slow and fast-twitch fiber types, based on expression of distinct myosin heavy chain isoforms and different metabolic capabilities (Baskin et al., 2015; Talbot and Maves, 2016). Oost et al. (2019) did not find any difference in terms of fiber type distribution, fiber size, or muscle force in skeletal muscle-specific FGF21 KO mice, which suggests that skeletal muscle-derived FGF21 does not contribute to embryonic myogenesis and muscle fiber determination under normal conditions. However, studies have demonstrated that myoblasts express considerable amounts of FGF21 during myogenic differentiation (Ribas et al., 2014; Liu et al., 2017). Myoblast-derived FGF21 facilitates the switching of the muscle fiber type from anaerobic to aerobic myofibers via stimulation of the FGF21-sirtuin type 1 (SIRT1)-AMPKPPAR g coactivator $1 \mathrm{a}(\mathrm{PGC} 1 \alpha)$ axis in vitro on $\mathrm{C} 2 \mathrm{C} 12$ cells and in vivo on skeletal muscle-specific FGF21 transgenic mice (Liu et al., 2017). It is therefore of interest to know if musclederived FGF21 plays a role in muscle fiber type switching under pathological conditions that are accompanied by elevated FGF21 expression from skeletal muscle, and whether the resulting muscle fiber type is an adaptive or causative response to the primary pathology.

Mitochondria are critical for cellular energy generation and biosynthetic pathways and regulation of their function is paramount for muscle physiology and metabolism (Hood et al., 2019). Multiple studies have demonstrated enhanced mitochondrial biogenesis and oxidative functions in both liver and adipose tissue under the treatment of FGF21. Specifically, FGF21 regulates mitochondrial oxidative function in adipocytes via the AMPK-SIRT1-PGC1 $\alpha$ pathway (Chau et al., 2010). In liver, pathways involved in activation of PGC1 $\alpha$ were also observed in FGF21 transgenic mice and WT mice treated with FGF21 (Potthoff et al., 2009; Fisher et al., 2011). However, if a similar signaling pathway is also present in skeletal muscle remains unknown. Since FGF21 is induced in and secreted from skeletal muscle in mitochondrial myopathies and various mitochondrial stressors, it might also act as an adaptive mediator of the muscle mitochondrial stress via activation of pathways that control mitochondrial function (Oost et al., 2019, 2020; Klaus and Ost, 2020). It would be of interest to determine whether FGF21 also regulates mitochondrial biogenesis and function in muscle via activation of AMPK, SIRT1, and PGC1 $\alpha$.

\section{THE EFFECTS OF FGF21 ON BONE}

Whether FGF21 has a positive or detrimental effect on bone in mice and humans remains unclear. Studies have shown that FGF21-Tg mice and mice administrated recombinant FGF21 have reduced bone mass (Wei et al., 2012; Zhang et al., 2012). Increased serum FGF21 has also been reported to negatively affect bone mineral density (BMD) during lactation in C57BL/6 mice (Bornstein et al., 2014). Moreover, in a mouse model of DMD, which shows elevated circulating skeletal muscle-derived FGF21 (Zhou et al., 2018), blockage of FGF21's action using a neutralization antibody, resulted in significantly increased bone mass and improved quality of bone tissues ( $\mathrm{Li}$ et al., 2020). However, conflicting data exists as others have reported no bone loss observed in FGF21 $\mathrm{KO}$ mice nor in recombinant FGF21 treated mice (Li et al., 2017). Additionally, no significant bone loss was detected in AAV8-hAAT-FGF-21 genetically engineered high fat dietinduced obese mice (Jimenez et al., 2018).

Inconsistencies are also found in human studies. Plasma FGF21 concentrations have been shown to negatively correlate with femoral neck BMD in a Han Chinese adult population (Hao et al., 2018) and in healthy aged adults (Lee et al., 2020). Serum FGF21 levels were found to be associated with worsened radial trabecular bone microarchitecture and decreased radial bone strength in women with anorexia nervosa (Fazeli et al., 2015a). Elevated FGF21 levels are also associated with poor bone health in HIV-1 infected patients (GallegoEscuredo et al., 2017). Obese humans and non-human primates administered a long-acting FGF21 analog demonstrated increased plasma biomarkers of bone resorption and decreased bone formation, which indicates bone loss (Talukdar et al., 2016; Kim et al., 2017). On the other hand, others have reported no clear correlation of serum FGF21 with BMD and fragility fractures (Choi et al., 2018; Hu et al., 2018). Furthermore, an independent positive association between plasma FGF21 levels and BMD in 40 healthy young women has also been reported (Lee et al., 2013). The inconsistency may be due to the heterogeneous populations and disease states; the effects of FGF21 on bone health are likely duration and context-dependent. Future studies should consider the influence of underlying diseases.

Although the exact mechanism of how FGF21 regulates bone homeostasis is still not clear, several direct and indirect mechanisms have been proposed (Figure 2). The expression of FGFRs/ $\beta$-klotho in bone tissue has not been fully established, however, a recent study on dystrophic mice demonstrated that $\beta$-klotho and FGFR expression is significantly induced in mature osteoclasts ( $\mathrm{Li}$ et al., 2020). These data indicate that bone is a direct target of FGF21 and FGF21 may affect osteoclastogenesis in DMD. In addition to the direct effects, accumulating evidence also suggests indirect effects of FGF21 on bone. Studies have shown direct stimulation of adipogenesis in bone marrow-derived mesenchymal stem cells by FGF21 (Wei et al., 2012; Li et al., 2020). FGF21 has close connections with the somatotropic axis, which plays an important role in protein synthesis and bone homeostasis (Milman et al., 2016). 
Transgenic mice overexpressing FGF21 showed evidence of growth hormone $(\mathrm{GH})$ resistance in the liver, which significantly reduced the level of serum insulin-like growth factor-1 (IGF-1; Inagaki et al., 2008; Kubicky et al., 2012). FGF21 blunts hepatic GH signaling via inhibition of STAT5 signaling, increased expression of IGF-1 binding protein 1 (IGFBP-1), and increased expression of suppressor of cytokine signaling 2 (SOCS2; Inagaki et al., 2008). In addition, FGF21 inhibits GH's action on proliferation and differentiation of chondrocytes directly at the growth plate (Wu et al., 2012, 2013). Moreover, Wei et al. (2012) reported that FGF21 promotes IGFBP-1 release from liver, which consequently enhanced osteoclastogenesis and provoked bone resorption. Interestingly, elevated IGFBP-1 was not observed in DMD animal models (Li et al., 2020) and in aged populations (Lee et al., 2020), both of which demonstrate elevated serum FGF21 and pathologic bone changes.

Although the clinical data are still controversial and further studies are needed to address the molecular mechanisms of FGF-21's action on bone, the current literature suggests adverse effects of FGF21 on bones, which needs to be carefully addressed in future human studies.

\section{DISCREPANCIES BETWEEN MICE AND HUMANS}

An abundance of data has been generated in mice and revealed several mechanistic findings with regards to FGF21 expression, regulation, and function. However, as literature regarding FGF21 analysis in humans has expanded, differences between mice and humans have been identified and recently reviewed (Staiger et al., 2017; Keuper et al., 2020). The discrepancies include circulating FGF21 levels, tissue-specific expression and regulation, and its role in glucose and lipid metabolism in addition to metabolic diseases.

Serum levels of FGF21 not only vary significantly between mice and humans but within the species themselves. In mice, serum FGF21 concentrations in chow-fed mice range from 0.1 to $3,000 \mathrm{ng} / \mathrm{ml}$ (Badman et al., 2007; Fisher et al., 2010; Dutchak et al., 2012; Murata et al., 2013; Tezze et al., 2017; Jimenez et al., 2018). Further complicating data interpretation, variations in mouse serum FGF21 are dependent on the strain tested, animal age, phase of the circadian cycle, and the assay used to quantify serum levels (Tezze et al., 2019). Wide variability also exists in healthy humans with published serum concentrations of FGF21 ranging from 21 to $7,100 \mathrm{pg} / \mathrm{ml}$ (Galman et al., 2008; Zhang et al., 2008; Li et al., 2009; Dushay et al., 2010; Kralisch et al., 2013; Fazeli et al., 2015b).

While FGF21 gene expression in murine models occurs in the liver, pancreas, adipose tissue, skeletal muscle, and other tissues in the basal state (Nishimura et al., 2000; Itoh, 2014; Petryszak et al., 2016), our current understanding is that the liver expresses and releases into the circulation the majority of FGF21 in healthy humans (Dushay et al., 2010; Petryszak et al., 2016; Keuper et al., 2020). However, it should be noted that most in vivo human data are correlational in nature, lacking mechanistic insights.

With regards to the regulation of FGF21 in mice and humans, protein restriction, fructose ingestion, exercise, and circadian clock machinery all induce hepatic expression and elevated circulating levels of FGF21 in both species (Staiger et al., 2017). Similarities also exist with the stimulation of FGF21 from skeletal muscle during conditions of muscle-specific mitochondrial disease, certain types of exercise, and hyperinsulinemia in mice and humans (Hojman et al., 2009; Crooks et al., 2014; Emanuelli et al., 2014; Tanimura et al., 2016; Staiger et al., 2017). As previously discussed, inter-species discrepancies exist with regards to the impact of nutritional stressors on circulating and muscle-derived FGF21. Nutrient deprivation/fasting and consumption of ketogenic diets result in a rapid rise of FGF21 serum levels in mice (Badman et al., 2007), however, elevations of FGF21 are only seen in humans after prolonged fasting period of at least 7 days (Galman et al., 2008; Fazeli et al., 2015b). Moreover, differences also exist between species in response to hormone inducers. In mouse models, studies have shown an increase in hepatic-derived serum FGF21 levels in response to $\mathrm{GH}$ administration (Chen et al., 2011) and thyroid hormone (Adams et al., 2010; Domouzoglou et al., 2014), however, no acute effect on serum FGF21 was seen in humans in response to $\mathrm{GH}$ or thyroid hormone administration (Lundberg et al., 2013; Bonde et al., 2014).

Although caution should be taken when translating murine study results to humans, mouse models of FGF21 expression serve an invaluable role in elucidating the complex interplay of this hormone in human physiology and disease.

\section{CONCLUSION AND FUTURE PERSPECTIVES}

Our understanding of the role of FGF21 in biological systems has advanced enormously over the last two decades. Although the main function of FGF21 as a starvation-induced hormone secreted from the liver has been known and broadly understood for some time, the ectopic expression and secretion of FGF21 from skeletal muscle and its potential role in a range of mitochondrial and muscular disorders is increasingly recognized. There is compelling evidence to indicate novel effects of FGF21 on skeletal muscle and bone, however, many outstanding questions remain. (1) Although many studies have observed and reported the phenotypic changes in skeletal muscle and bone in the presence of elevated FGF21, compared to our understanding of the function of FGF21 on liver and adipose tissue, the mechanism(s) of its action on skeletal muscle and bone is still largely unknown. More work is required to elucidate the cellular and molecular mechanisms of muscle-derived FGF21 and to understand its regulation and function at the whole-body level. (2) Clinical validation of FGF21 as a biomarker of disease and potential therapeutic target in mitochondrial myopathies and DMD is still needed. (3) With the unraveling of the cross-interactions with other signaling pathways, such as AMPK-SIRT1 (Chau et al., 2010), GH (Inagaki et al., 2008; Wu et al., 2012), and glucocorticoids 
(Patel et al., 2015), the effects of muscle-derived FGF21 might be pathological context-dependent. Our understanding of the pathologic role and even the pharmacologic effects of FGF21 need to be more disease/condition specific. (4) Additionally, although some mechanisms have been proposed, the exact cellular and molecular mechanisms of FGF21 secretion from skeletal muscle under different pathological conditions and the target cells within the musculoskeletal system, specifically skeletal muscle and bone, are still largely unknown. A promising approach towards understanding the mechanism of FGF21 includes continued development of tissue-specific FGF21 and/or $\beta$-klotho receptor/KO animal models. Furthermore, tissue-specific receptor and/or $\mathrm{KO}$ animal models based on specific disease conditions will also be needed to understand the role of FGF21 under a specific pathological context.

\section{REFERENCES}

Adams, A. C., Astapova, I., Fisher, F. M., Badman, M. K., Kurgansky, K. E., Flier, J. S., et al. (2010). Thyroid hormone regulates hepatic expression of fibroblast growth factor 21 in a PPARalpha-dependent manner. J. Biol. Chem. 285, 14078-14082. doi: 10.1074/jbc.C110.107375

Addison, O., Marcus, R. L., Lastayo, P. C., and Ryan, A. S. (2014). Intermuscular fat: a review of the consequences and causes. Int. J. Endocrinol. 2014:309570. doi: 10.1155/2014/309570

Andersen, T. R., Schmidt, J. F., Thomassen, M., Hornstrup, T., Frandsen, U., Randers, M. B., et al. (2014). A preliminary study: effects of football training on glucose control, body composition, and performance in men with type 2 diabetes. Scand. J. Med. Sci. Sports 24, 43-56. doi: 10.1111/ sms. 12259

Badenhorst, C. E., Dawson, B., Cox, G. R., Laarakkers, C. M., Swinkels, D. W., and Peeling, P. (2015). Acute dietary carbohydrate manipulation and the subsequent inflammatory and hepcidin responses to exercise. Eur. J. Appl. Physiol. 115, 2521-2530. doi: 10.1007/s00421-015-3252-3

Badman, M. K., Pissios, P., Kennedy, A. R., Koukos, G., Flier, J. S., and Maratos-Flier, E. (2007). Hepatic fibroblast growth factor 21 is regulated by PPARalpha and is a key mediator of hepatic lipid metabolism in ketotic states. Cell Metab. 5, 426-437. doi: 10.1016/j.cmet.2007.05.002

Bandet, C. L., Tan-Chen, S., Bourron, O., Le Stunff, H., and Hajduch, E. (2019). Sphingolipid metabolism: new insight into ceramide-induced lipotoxicity in muscle cells. Int. J. Mol. Sci. 20:479. doi: 10.3390/ijms20030479

Baskin, K. K., Winders, B. R., and Olson, E. N. (2015). Muscle as a "mediator" of systemic metabolism. Cell Metab. 21, 237-248. doi: 10.1016/j.cmet. 2014.12.021

Benoit, B., Meugnier, E., Castelli, M., Chanon, S., Vieille-Marchiset, A., Durand, C., et al. (2017). Fibroblast growth factor 19 regulates skeletal muscle mass and ameliorates muscle wasting in mice. Nat. Med. 23, 990-996. doi: 10.1038/ nm.4363

Berglund, E. D., Lustig, D. G., Baheza, R. A., Hasenour, C. M., Lee-Young, R. S., Donahue, E. P., et al. (2011). Hepatic glucagon action is essential for exerciseinduced reversal of mouse fatty liver. Diabetes 60, 2720-2729. doi: 10.2337/ db11-0455

Besse-Patin, A., Montastier, E., Vinel, C., Castan-Laurell, I., Louche, K., Dray, C., et al. (2014). Effect of endurance training on skeletal muscle myokine expression in obese men: identification of apelin as a novel myokine. Int. J. Obes. 38, 707-713. doi: 10.1038/ijo.2013.158

Bonde, Y., Breuer, O., Lutjohann, D., Sjoberg, S., Angelin, B., and Rudling, M. (2014). Thyroid hormone reduces PCSK9 and stimulates bile acid synthesis in humans. J. Lipid Res. 55, 2408-2415. doi: 10.1194/jlr.M051664

BonDurant, L. D., and Potthoff, M. J. (2018). Fibroblast growth factor 21: a versatile regulator of metabolic homeostasis. Annu. Rev. Nutr. 38, 173-196. doi: 10.1146/annurev-nutr-071816-064800

\section{AUTHOR CONTRIBUTIONS}

HS and MS performed reference analysis and manuscript preparation. HL designed research (project conception, development of overall research plan, and oversight) and had primary responsibility for final content, reference analysis, and manuscript preparation. All authors contributed to the article and approved the submitted version.

\section{FUNDING}

This work was mainly supported by NIH R01 to HL (1R01AR076357-01). This work was partially supported by the Competitive Medical Research Fund of the UMPC Health System to HL and by Foundation for Physical Medicine and Rehabilitation to HL and MS (00022613).

Bookout, A. L., de Groot, M. H., Owen, B. M., Lee, S., Gautron, L., Lawrence, H. L., et al. (2013). FGF21 regulates metabolism and circadian behavior by acting on the nervous system. Nat. Med. 19, 1147-1152. doi: 10.1038/nm.3249

Bornstein, S., Brown, S. A., Le, P. T., Wang, X., DeMambro, V., Horowitz, M. C., et al. (2014). FGF-21 and skeletal remodeling during and after lactation in C57BL/6J mice. Endocrinology 155, 3516-3526. doi: 10.1210/en. 2014-1083

Canto, C., and Auwerx, J. (2012). Cell biology. FGF21 takes a fat bite. Science 336, 675-676. doi: 10.1126/science.1222646

Chau, M. D., Gao, J., Yang, Q., Wu, Z., and Gromada, J. (2010). Fibroblast growth factor 21 regulates energy metabolism by activating the AMPKSIRT1-PGC-1alpha pathway. Proc. Natl. Acad. Sci. U. S. A. 107, 12553-12558. doi: 10.1073/pnas.1006962107

Chen, W., Hoo, R. L., Konishi, M., Itoh, N., Lee, P. C., Ye, H. Y., et al. (2011). Growth hormone induces hepatic production of fibroblast growth factor 21 through a mechanism dependent on lipolysis in adipocytes. J. Biol. Chem. 286, 34559-34566. doi: 10.1074/jbc.M111.285965

Choi, H. S., Lee, H. A., Kim, S. W., and Cho, E. H. (2018). Association between serum fibroblast growth factor 21 levels and bone mineral density in postmenopausal women. Endocrinol. Metab. 33, 273-277. doi: 10.3803/ EnM.2018.33.2.273

Coen, P. M., and Goodpaster, B. H. (2012). Role of intramyocelluar lipids in human health. Trends Endocrinol. Metab. 23, 391-398. doi: 10.1016/j. tem.2012.05.009

Conte, M., Ostan, R., Fabbri, C., Santoro, A., Guidarelli, G., Vitale, G., et al. (2018). Human aging and longevity are characterized by high levels of mitokines. J. Gerontol. A Biol. Sci. Med. Sci. 74, 600-607. doi: 10.1093/ gerona/gly153

Crooks, D. R., Natarajan, T. G., Jeong, S. Y., Chen, C., Park, S. Y., Huang, H., et al. (2014). Elevated FGF21 secretion, PGC-1alpha and ketogenic enzyme expression are hallmarks of iron-sulfur cluster depletion in human skeletal muscle. Hum. Mol. Genet. 23, 24-39. doi: 10.1093/hmg/ddt393

Cuevas-Ramos, D., Almeda-Valdes, P., Meza-Arana, C. E., Brito-Cordova, G., Gomez-Perez, F. J., Mehta, R., et al. (2012). Exercise increases serum fibroblast growth factor 21 (FGF21) levels. PLoS One 7:e38022. doi: 10.1371/journal. pone.0038022

De Palma, C., Morisi, F., Cheli, S., Pambianco, S., Cappello, V., Vezzoli, M., et al. (2012). Autophagy as a new therapeutic target in Duchenne muscular dystrophy. Cell Death Dis. 3:e418. doi: 10.1038/cddis.2012.159

Degirolamo, C., Sabbà, C., and Moschetta, A. (2016). Therapeutic potential of the endocrine fibroblast growth factors FGF19, FGF21 and FGF23. Nat. Rev. Drug Discov. 15, 51-69. doi: 10.1038/nrd.2015.9

Demontis, F., Piccirillo, R., Goldberg, A. L., and Perrimon, N. (2013). The influence of skeletal muscle on systemic aging and lifespan. Aging Cell 12, 943-949. doi: 10.1111/acel.12126 
Dolegowska, K., Marchelek-Mysliwiec, M., Nowosiad-Magda, M., Slawinski, M., and Dolegowska, B. (2019). FGF19 subfamily members: FGF19 and FGF21. J. Physiol. Biochem. 75, 229-240. doi: 10.1007/s13105-019-00675-7

Domouzoglou, E. M., Fisher, F. M., Astapova, I., Fox, E. C., Kharitonenkov, A., Flier, J. S., et al. (2014). Fibroblast growth factor 21 and thyroid hormone show mutual regulatory dependency but have independent actions in vivo. Endocrinology 155, 2031-2040. doi: 10.1210/en.2013-1902

Dushay, J., Chui, P. C., Gopalakrishnan, G. S., Varela-Rey, M., Crawley, M., Fisher, F. M., et al. (2010). Increased fibroblast growth factor 21 in obesity and nonalcoholic fatty liver disease. Gastroenterology 139, 456-463. doi: 10.1053/j.gastro.2010.04.054

Dutchak, P. A., Katafuchi, T., Bookout, A. L., Choi, J. H., Yu, R. T., Mangelsdorf, D. J., et al. (2012). Fibroblast growth factor-21 regulates PPARgamma activity and the antidiabetic actions of thiazolidinediones. Cell 148, 556-567. doi: 10.1016/j.cell.2011.11.062

Edmonston, D., and Wolf, M. (2020). FGF23 at the crossroads of phosphate, iron economy and erythropoiesis. Nat. Rev. Nephrol. 16, 7-19. doi: 10.1038/ s41581-019-0189-5

Emanuelli, B., Vienberg, S. G., Smyth, G., Cheng, C., Stanford, K. I., Arumugam, M., et al. (2014). Interplay between FGF21 and insulin action in the liver regulates metabolism. J. Clin. Invest. 124, 515-527. doi: 10.1172/ JCI67353

Fazeli, P. K., Faje, A. T., Cross, E. J., Lee, H., Rosen, C. J., Bouxsein, M. L., et al. (2015a). Serum FGF-21 levels are associated with worsened radial trabecular bone microarchitecture and decreased radial bone strength in women with anorexia nervosa. Bone 77, 6-11. doi: 10.1016/j.bone.2015.04.001

Fazeli, P. K., Lun, M., Kim, S. M., Bredella, M. A., Wright, S., Zhang, Y., et al. (2015b). FGF21 and the late adaptive response to starvation in humans. J. Clin. Invest. 125, 4601-4611. doi: 10.1172/JCI83349

Fisher, F. M., Chui, P. C., Antonellis, P. J., Bina, H. A., Kharitonenkov, A., Flier, J. S., et al. (2010). Obesity is a fibroblast growth factor 21 (FGF21)resistant state. Diabetes 59, 2781-2789. doi: 10.2337/db10-0193

Fisher, F. M., Estall, J. L., Adams, A. C., Antonellis, P. J., Bina, H. A., Flier, J. S., et al. (2011). Integrated regulation of hepatic metabolism by fibroblast growth factor 21 (FGF21) in vivo. Endocrinology 152, 2996-3004. doi: 10.1210/ en.2011-0281

Fisher, F. M., and Maratos-Flier, E. (2016). Understanding the physiology of FGF21. Annu. Rev. Physiol. 78, 223-241. doi: 10.1146/annurev-physiol021115-105339

Fletcher, J. A., Linden, M. A., Sheldon, R. D., Meers, G. M., Morris, E. M., Butterfield, A., et al. (2016). Fibroblast growth factor 21 and exercise-induced hepatic mitochondrial adaptations. Am. J. Physiol. Gastrointest. Liver Physiol. 310, G832-G843. doi: 10.1152/ajpgi.00355.2015

Gallego-Escuredo, J. M., Lamarca, M. K., Villarroya, J., Domingo, J. C., Mateo, M. G., Gutierrez, M. D. M., et al. (2017). High FGF21 levels are associated with altered bone homeostasis in HIV-1-infected patients. Metabolism 71, 163-170. doi: 10.1016/j.metabol.2017.03.014

Galman, C., Lundasen, T., Kharitonenkov, A., Bina, H. A., Eriksson, M., Hafstrom, I., et al. (2008). The circulating metabolic regulator FGF21 is induced by prolonged fasting and PPARalpha activation in man. Cell Metab. 8, 169-174. doi: 10.1016/j.cmet.2008.06.014

Guridi, M., Tintignac, L. A., Lin, S., Kupr, B., Castets, P., and Ruegg, M. A. (2015). Activation of mTORC1 in skeletal muscle regulates whole-body metabolism through FGF21. Sci. Signal. 8:ra113. doi: 10.1126/scisignal. aab3715

Hale, C., Chen, M. M., Stanislaus, S., Chinookoswong, N., Hager, T., Wang, M., et al. (2012). Lack of overt FGF21 resistance in two mouse models of obesity and insulin resistance. Endocrinology 153, 69-80. doi: 10.1210/ en.2010-1262

Hanks, L. J., Gutierrez, O. M., Bamman, M. M., Ashraf, A., McCormick, K. L., and Casazza, K. (2015). Circulating levels of fibroblast growth factor-21 increase with age independently of body composition indices among healthy individuals. J. Clin. Transl. Endocrinol. 2, 77-82. doi: 10.1016/j.jcte.2015.02.001

Hansen, J. S., Clemmesen, J. O., Secher, N. H., Hoene, M., Drescher, A., Weigert, C., et al. (2015). Glucagon-to-insulin ratio is pivotal for splanchnic regulation of FGF-21 in humans. Mol. Metab. 4, 551-560. doi: 10.1016/j. molmet.2015.06.001

Hansen, J. S., Pedersen, B. K., Xu, G., Lehmann, R., Weigert, C., and Plomgaard, P. (2016). Exercise-induced secretion of FGF21 and follistatin are blocked by pancreatic clamp and impaired in type 2 diabetes. J. Clin. Endocrinol. Metab. 101, 2816-2825. doi: 10.1210/jc.2016-1681

Hao, R. H., Gao, J. L., Li, M., Huang, W., Zhu, D. L., Thynn, H. N., et al. (2018). Association between fibroblast growth factor 21 and bone mineral density in adults. Endocrine 59, 296-303. doi: 10.1007/s12020-017-1507-y

Harris, L. A., Skinner, J. R., Shew, T. M., Pietka, T. A., Abumrad, N. A., and Wolins, N. E. (2015). Perilipin 5-driven lipid droplet accumulation in skeletal muscle stimulates the expression of fibroblast growth factor 21. Diabetes 64, 2757-2768. doi: 10.2337/db14-1035

Henkel, A. S., Anderson, K. A., Dewey, A. M., Kavesh, M. H., and Green, R. M. (2011). A chronic high-cholesterol diet paradoxically suppresses hepatic CYP7A1 expression in FVB/NJ mice. J. Lipid Res. 52, 289-298. doi: 10.1194/ jlr.M012781

Hojman, P., Pedersen, M., Nielsen, A. R., Krogh-Madsen, R., Yfanti, C., Akerstrom, T., et al. (2009). Fibroblast growth factor-21 is induced in human skeletal muscles by hyperinsulinemia. Diabetes 58, 2797-2801. doi: 10.2337/ db09-0713

Holt, J. A., Luo, G., Billin, A. N., Bisi, J., McNeill, Y. Y., Kozarsky, K. F., et al. (2003). Definition of a novel growth factor-dependent signal cascade for the suppression of bile acid biosynthesis. Genes Dev. 17, 1581-1591. doi: 10.1101/gad.1083503

Hommelberg, P. P., Plat, J., Sparks, L. M., Schols, A. M., van Essen, A. L., Kelders, M. C., et al. (2011). Palmitate-induced skeletal muscle insulin resistance does not require NF-kappaB activation. Cell. Mol. Life Sci. 68, 1215-1225. doi: 10.1007/s00018-010-0515-3

Hood, D. A., Memme, J. M., Oliveira, A. N., and Triolo, M. (2019). Maintenance of skeletal muscle mitochondria in health, exercise, and aging. Annu. Rev. Physiol. 81, 19-41. doi: 10.1146/annurev-physiol-020518-114310

$\mathrm{Hu}$, W., He, J., Fu, W., Wang, C., Yue, H., Gu, J., et al. (2018). Fibroblast growth factor 21 is associated with bone mineral density, but not with bone turnover markers and fractures in Chinese postmenopausal women. J. Clin. Densitom. 22, 179-184. doi: 10.1016/j.jocd.2018.08.005

Hui, X., Feng, T., Liu, Q., Gao, Y., and Xu, A. (2016). The FGF21-adiponectin axis in controlling energy and vascular homeostasis. J. Mol. Cell Biol. 8, 110-119. doi: 10.1093/jmcb/mjw013

Inagaki, T., Dutchak, P., Zhao, G., Ding, X., Gautron, L., Parameswara, V., et al. (2007). Endocrine regulation of the fasting response by PPARalphamediated induction of fibroblast growth factor 21. Cell Metab. 5, 415-425. doi: 10.1016/j.cmet.2007.05.003

Inagaki, T., Lin, V. Y., Goetz, R., Mohammadi, M., Mangelsdorf, D. J., and Kliewer, S. A. (2008). Inhibition of growth hormone signaling by the fasting-induced hormone FGF21. Cell Metab. 8, 77-83. doi: 10.1016/j. cmet.2008.05.006

Ito, S., Kinoshita, S., Shiraishi, N., Nakagawa, S., Sekine, S., Fujimori, T., et al. (2000). Molecular cloning and expression analyses of mouse betaklotho, which encodes a novel Klotho family protein. Mech. Dev. 98, 115-119. doi: 10.1016/s0925-4773(00)00439-1

Itoh, N. (2014). FGF21 as a hepatokine, adipokine, and myokine in metabolism and diseases. Front. Endocrinol. 5:107. doi: 10.3389/fendo.2014.00107

Izaguirre, M., Gil, M. J., Monreal, I., Montecucco, F., Fruhbeck, G., and Catalan, V. (2017). The role and potential therapeutic implications of the fibroblast growth factors in energy balance and type 2 diabetes. Curr. Diab. Rep. 17:43. doi: 10.1007/s11892-017-0866-3

Izumiya, Y., Bina, H. A., Ouchi, N., Akasaki, Y., Kharitonenkov, A., and Walsh, K. (2008). FGF21 is an Akt-regulated myokine. FEBS Lett. 582, 3805-3810. doi: 10.1016/j.febslet.2008.10.021

Jensen-Cody, S. O., Flippo, K. H., Claflin, K. E., Yavuz, Y., Sapouckey, S. A., Walters, G. C., et al. (2020). FGF21 signals to glutamatergic neurons in the ventromedial hypothalamus to suppress carbohydrate intake. Cell Metab. 32, 273-286.e276. doi: 10.1016/j.cmet.2020.06.008

Jeon, J. Y., Choi, S. E., Ha, E. S., Kim, T. H., Jung, J. G., Han, S. J., et al. (2016). Association between insulin resistance and impairment of FGF21 signal transduction in skeletal muscles. Endocrine 53, 97-106. doi: 10.1007/ s12020-015-0845-x

Jimenez, V., Jambrina, C., Casana, E., Sacristan, V., Munoz, S., Darriba, S., et al. (2018). FGF21 gene therapy as treatment for obesity and insulin resistance. EMBO Mol. Med. 10:e8791. doi: 10.15252/emmm.201708791

Jung, J. G., Yi, S. A., Choi, S. E., Kang, Y., Kim, T. H., Jeon, J. Y., et al. (2015). TM-25659-induced activation of FGF21 level decreases insulin 
resistance and inflammation in skeletal muscle via GCN2 pathways. Mol. Cells 38, 1037-1043. doi: 10.14348/molcells.2015.0100

Keipert, S., Ost, M., Johann, K., Imber, F., Jastroch, M., van Schothorst, E. M., et al. (2014). Skeletal muscle mitochondrial uncoupling drives endocrine cross-talk through the induction of FGF21 as a myokine. Am. J. Physiol. Endocrinol. Metab. 306, E469-E482. doi: 10.1152/ajpendo.00330.2013

Keuper, M., Haring, H. U., and Staiger, H. (2020). Circulating FGF21 levels in human health and metabolic disease. Exp. Clin. Endocrinol. Diabetes 128, 752-770. doi: 10.1055/a-0879-2968

Khan, N. A., Nikkanen, J., Yatsuga, S., Jackson, C., Wang, L., Pradhan, S., et al. (2017). mTORC1 regulates mitochondrial integrated stress response and mitochondrial myopathy progression. Cell Metab. 26, 419-428.e415. doi: 10.1016/j.cmet.2017.07.007

Kharitonenkov, A., Shiyanova, T. L., Koester, A., Ford, A. M., Micanovic, R., Galbreath, E. J., et al. (2005). FGF-21 as a novel metabolic regulator. J. Clin. Invest. 115, 1627-1635. doi: 10.1172/JCI23606

Kim, K. H., Jeong, Y. T., Oh, H., Kim, S. H., Cho, J. M., Kim, Y. N., et al. (2013a). Autophagy deficiency leads to protection from obesity and insulin resistance by inducing Fgf21 as a mitokine. Nat. Med. 19, 83-92. doi: 10.1038/ nm.3014

Kim, K. H., Kim, S. H., Min, Y. K., Yang, H. M., Lee, J. B., and Lee, M. S. (2013b). Acute exercise induces FGF21 expression in mice and in healthy humans. PLoS One 8:e63517. doi: 10.1371/journal.pone.0063517

Kim, K. H., and Lee, M. S. (2014). FGF21 as a stress hormone: the roles of FGF21 in stress adaptation and the treatment of metabolic diseases. Diabetes Metab. J. 38, 245-251. doi: 10.4093/dmj.2014.38.4.245

Kim, A. M., Somayaji, V. R., Dong, J. Q., Rolph, T. P., Weng, Y., Chabot, J. R., et al. (2017). Once-weekly administration of a long-acting fibroblast growth factor 21 analogue modulates lipids, bone turnover markers, blood pressure and body weight differently in obese people with hypertriglyceridaemia and in non-human primates. Diabetes Obes. Metab. 19, 1762-1772. doi: 10.1111/ dom. 13023

Klaus, S., and Ost, M. (2020). Mitochondrial uncoupling and longevity - a role for mitokines? Exp. Gerontol. 130:110796. doi: 10.1016/j.exger.2019.110796

Kralisch, S., Tonjes, A., Krause, K., Richter, J., Lossner, U., Kovacs, P., et al. (2013). Fibroblast growth factor-21 serum concentrations are associated with metabolic and hepatic markers in humans. J. Endocrinol. 216, 135-143. doi: 10.1530/JOE-12-0367

Kruse, R., Vienberg, S. G., Vind, B. F., Andersen, B., and Højlund, K. (2017). Effects of insulin and exercise training on FGF21, its receptors and target genes in obesity and type 2 diabetes. Diabetologia 60, 2042-2051. doi: 10.1007/s00125-017-4373-5

Kubicky, R. A., Wu, S., Kharitonenkov, A., and De Luca, F. (2012). Role of fibroblast growth factor 21 (FGF21) in undernutrition-related attenuation of growth in mice. Endocrinology 153, 2287-2295. doi: 10.1210/en.2011-1909

Lee, M. S., Choi, S. E., Ha, E. S., An, S. Y., Kim, T. H., Han, S. J., et al. (2012). Fibroblast growth factor-21 protects human skeletal muscle myotubes from palmitate-induced insulin resistance by inhibiting stress kinase and NF-kappaB. Metabolism 61, 1142-1151. doi: 10.1016/j.metabol.2012.01.012

Lee, S. Y., Fam, K. D., Chia, K. L., Yap, M. M. C., Goh, J., Yeo, K. P., et al. (2020). Age-related bone loss is associated with FGF21 but not IGFBP1 in healthy adults. Exp. Physiol. 105, 622-631. doi: 10.1113/EP088351

Lee, P., Linderman, J., Smith, S., Brychta, R. J., Perron, R., Idelson, C., et al. (2013). Fibroblast growth factor 21 (FGF21) and bone: is there a relationship in humans? Osteoporos. Int. 24, 3053-3057. doi: 10.1007/s00198-013-2464-9

Lehtonen, J. M., Auranen, M., Darin, N., Sofou, K., Bindoff, L., Hikmat, O., et al. (2020). Diagnostic value of serum biomarkers FGF21 and GDF15 compared to muscle sample in mitochondrial disease. J. Inherit. Metab. Dis. doi: 10.1002/jimd.12307 [Epub ahead of print]

Lehtonen, J. M., Forsstrom, S., Bottani, E., Viscomi, C., Baris, O. R., Isoniemi, H., et al. (2016). FGF21 is a biomarker for mitochondrial translation and mtDNA maintenance disorders. Neurology 87, 2290-2299. doi: 10.1212/WNL.000 0000000003374

Li, H., Bao, Y., Xu, A., Pan, X., Lu, J., Wu, H., et al. (2009). Serum fibroblast growth factor 21 is associated with adverse lipid profiles and gammaglutamyltransferase but not insulin sensitivity in Chinese subjects. J. Clin. Endocrinol. Metab. 94, 2151-2156. doi: 10.1210/jc.2008-2331

Li, X., Stanislaus, S., Asuncion, F., Niu, Q. T., Chinookoswong, N., Villasenor, K., et al. (2017). FGF21 is not a major mediator for bone homeostasis or metabolic actions of PPARalpha and PPARgamma agonists. J. Bone Miner. Res. 32, 834-845. doi: 10.1002/jbmr.2936

Li, H., Sun, H., Qian, B., Feng, W., Carney, D., Miller, J., et al. (2020). Increased expression of FGF-21 negatively affects bone homeostasis in dystrophin/ utrophin double knockout mice. J. Bone Miner. Res. 35, 738-752. doi: 10.1002/ jbmr.3932

Lin, Z., Tian, H., Lam, K. S., Lin, S., Hoo, R. C., Konishi, M., et al. (2013). Adiponectin mediates the metabolic effects of FGF21 on glucose homeostasis and insulin sensitivity in mice. Cell Metab. 17, 779-789. doi: 10.1016/j. cmet.2013.04.005

Lipina, C., and Hundal, H. S. (2017). Lipid modulation of skeletal muscle mass and function. J. Cachexia. Sarcopenia Muscle 8, 190-201. doi: 10.1002/ jcsm. 12144

Liu, J. J., Foo, J. P., Liu, S., and Lim, S. C. (2015). The role of fibroblast growth factor 21 in diabetes and its complications: a review from clinical perspective. Diabetes Res. Clin. Pract. 108, 382-389. doi: 10.1016/j.diabres. 2015.02.032

Liu, X., Wang, Y., Hou, L., Xiong, Y., and Zhao, S. (2017). Fibroblast growth factor 21 (FGF21) promotes formation of aerobic myofibers via the FGF21SIRT1-AMPK-PGC1 $\alpha$ pathway. J. Cell. Physiol. 232, 1893-1906. doi: 10.1002/ jcp. 25735

Lovadi, E., Csereklyei, M., Merkli, H., FüLöp, K., Sebők, Á., Karcagi, V., et al. (2017). Elevated FGF 21 in myotonic dystrophy type 1 and mitochondrial diseases. Muscle Nerve 55, 564-569. doi: 10.1002/mus.25364

Loyd, C., Magrisso, I. J., Haas, M., Balusu, S., Krishna, R., Itoh, N., et al. (2016). Fibroblast growth factor 21 is required for beneficial effects of exercise during chronic high-fat feeding. J. Appl. Physiol. 121, 687-698. doi: 10.1152/ japplphysiol.00456.2016

Lundasen, T., Hunt, M. C., Nilsson, L. M., Sanyal, S., Angelin, B., Alexson, S. E., et al. (2007). PPARalpha is a key regulator of hepatic FGF21. Biochem. Biophys. Res. Commun. 360, 437-440. doi: 10.1016/j.bbrc.2007.06.068

Lundberg, J., Hoybye, C., Krusenstjerna-Hafstrom, T., Bina, H. A., Kharitonenkov, A., Angelin, B., et al. (2013). Influence of growth hormone on circulating fibroblast growth factor 21 levels in humans. J. Intern. Med. 274, 227-232. doi: 10.1111/joim.12112

Markan, K. R. (2018). Defining "FGF21 resistance" during obesity: controversy, criteria and unresolved questions. F1000Res 7:289. doi: 10.12688/f1000research. 14117.1

Markan, K. R., Naber, M. C., Ameka, M. K., Anderegg, M. D., Mangelsdorf, D. J., Kliewer, S. A., et al. (2014). Circulating FGF21 is liver derived and enhances glucose uptake during refeeding and overfeeding. Diabetes 63, 4057-4063. doi: $10.2337 / \mathrm{db} 14-0595$

Martinez-Garza, U., Torres-Oteros, D., Yarritu-Gallego, A., Marrero, P. F., Haro, D., and Relat, J. (2019). Fibroblast growth factor 21 and the adaptive response to nutritional challenges. Int. J. Mol. Sci. 20:4692. doi: 10.3390/ijms20194692

Mashili, F. L., Austin, R. L., Deshmukh, A. S., Fritz, T., Caidahl, K., Bergdahl, K., et al. (2011). Direct effects of FGF21 on glucose uptake in human skeletal muscle: implications for type 2 diabetes and obesity. Diabetes Metab. Res. Rev. 27, 286-297. doi: 10.1002/dmrr.1177

Milman, S., Huffman, D. M., and Barzilai, N. (2016). The somatotropic axis in human aging: framework for the current state of knowledge and future research. Cell Metab. 23, 980-989. doi: 10.1016/j.cmet.2016.05.014

Miyake, M., Nomura, A., Ogura, A., Takehana, K., Kitahara, Y., Takahara, K., et al. (2016). Skeletal muscle-specific eukaryotic translation initiation factor $2 \alpha$ phosphorylation controls amino acid metabolism and fibroblast growth factor 21-mediated non-cell-autonomous energy metabolism. FASEB J. 30, 798-812. doi: 10.1096/fj.15-275990

Montgomery, M. K., Mokhtar, R., Bayliss, J., Parkington, H. C., Suturin, V. M., Bruce, C. R., et al. (2018). Perilipin 5 deletion unmasks an endoplasmic reticulum stress-fibroblast growth factor 21 axis in skeletal muscle. Diabetes 67, 594-606. doi: $10.2337 / \mathrm{db} 17-0923$

Morville, T., Sahl, R. E., Trammell, S. A., Svenningsen, J. S., Gillum, M. P., Helge, J. W., et al. (2018). Divergent effects of resistance and endurance exercise on plasma bile acids, FGF19, and FGF21 in humans. JCI Insight 3:e122737. doi: 10.1172/jci.insight.122737

Muise, E. S., Azzolina, B., Kuo, D. W., El-Sherbeini, M., Tan, Y., Yuan, X., et al. (2008). Adipose fibroblast growth factor 21 is up-regulated by peroxisome proliferator-activated receptor gamma and altered metabolic states. Mol. Pharmacol. 74, 403-412. doi: 10.1124/mol.108.044826 
Muoio, D. M. (2010). Intramuscular triacylglycerol and insulin resistance: guilty as charged or wrongly accused? Biochim. Biophys. Acta 1801, 281-288. doi: 10.1016/j.bbalip.2009.11.007

Muoio, D. M., and Newgard, C. B. (2008). Mechanisms of disease: molecular and metabolic mechanisms of insulin resistance and beta-cell failure in type 2 diabetes. Nat. Rev. Mol. Cell Biol. 9, 193-205. doi: 10.1038/nrm2327

Murata, Y., Nishio, K., Mochiyama, T., Konishi, M., Shimada, M., Ohta, H., et al. (2013). Fgf21 impairs adipocyte insulin sensitivity in mice fed a low-carbohydrate, high-fat ketogenic diet. PLoS One 8:e69330. doi: 10.1371/ journal.pone.0069330

Nishimura, T., Nakatake, Y., Konishi, M., and Itoh, N. (2000). Identification of a novel FGF, FGF-21, preferentially expressed in the liver. Biochim. Biophys. Acta 1492, 203-206. doi: 10.1016/s0167-4781(00)00067-1

Nygaard, E. B., Orskov, C., Almdal, T., Vestergaard, H., and Andersen, B. (2018). Fasting decreases plasma FGF21 in obese subjects and the expression of FGF21 receptors in adipose tissue in both lean and obese subjects. J. Endocrinol. 239, 73-80. doi: 10.1530/JOE-18-0002

Oost, L. J., Kustermann, M., Armani, A., Blaauw, B., and Romanello, V. (2019). Fibroblast growth factor 21 controls mitophagy and muscle mass. J. Cachexia. Sarcopenia Muscle 10, 630-642. doi: 10.1002/jcsm.12409

Oost, L. J., Sandri, M., and Romanello, V. (2020). The authors reply: letter on: "fibroblast growth factor 21 controls mitophagy and muscle mass" by Oost et al. J. Cachexia. Sarcopenia Muscle 11, 338-340. doi: 10.1002/jcsm.12500

Ost, M., Coleman, V., Kasch, J., and Klaus, S. (2016). Regulation of myokine expression: role of exercise and cellular stress. Free Radic. Biol. Med. 98, 78-89. doi: 10.1016/j.freeradbiomed.2016.02.018

Owen, B. M., Mangelsdorf, D. J., and Kliewer, S. A. (2015). Tissue-specific actions of the metabolic hormones FGF15/19 and FGF21. Trends Endocrinol. Metab. 26, 22-29. doi: 10.1016/j.tem.2014.10.002

Pakos-Zebrucka, K., Koryga, I., Mnich, K., Ljujic, M., Samali, A., and Gorman, A. M. (2016). The integrated stress response. EMBO Rep. 17, 1374-1395. doi: 10.15252/embr.201642195

Parmar, B., Lewis, J. E., Samms, R. J., Ebling, F. J. P., Cheng, C. C., Adams, A. C., et al. (2018). Eccentric exercise increases circulating fibroblast activation protein alpha but not bioactive fibroblast growth factor 21 in healthy humans. Exp. Physiol. 103, 876-883. doi: 10.1113/EP086669

Patel, R., Bookout, A. L., Magomedova, L., Owen, B. M., Consiglio, G. P., Shimizu, M., et al. (2015). Glucocorticoids regulate the metabolic hormone FGF21 in a feed-forward loop. Mol. Endocrinol. 29, 213-223. doi: 10.1210/ me.2014-1259

Pauly, M., Angebault-Prouteau, C., Dridi, H., Notarnicola, C., Scheuermann, V., Lacampagne, A., et al. (2017). ER stress disturbs SR/ER-mitochondria $\mathrm{Ca}^{2+}$ transfer: implications in Duchenne muscular dystrophy. Biochim. Biophys. Acta Mol. basis Dis. 1863, 2229-2239. doi: 10.1016/j.bbadis. 2017.06.009

Pedersen, B. K., Akerstrom, T. C., Nielsen, A. R., and Fischer, C. P. (2007). Role of myokines in exercise and metabolism. J. Appl. Physiol. (1985) 103, 1093-1098. doi: 10.1152/japplphysiol.00080.2007

Pedersen, B. K., and Febbraio, M. A. (2012). Muscles, exercise and obesity: skeletal muscle as a secretory organ. Nat. Rev. Endocrinol. 8, 457-465. doi: 10.1038/nrendo.2012.49

Pereira, R. O., Tadinada, S. M., Zasadny, F. M., Oliveira, K. J., Pires, K. M. P., Olvera, A., et al. (2017). OPA1 deficiency promotes secretion of FGF21 from muscle that prevents obesity and insulin resistance. EMBO J. 36, 2126-2145. doi: 10.15252/embj.201696179

Petryszak, R., Keays, M., Tang, Y. A., Fonseca, N. A., Barrera, E., Burdett, T., et al. (2016). Expression atlas update--an integrated database of gene and protein expression in humans, animals and plants. Nucleic Acids Res. 44, D746-D752. doi: 10.1093/nar/gkv1045

Potthoff, M. J., Inagaki, T., Satapati, S., Ding, X., He, T., Goetz, R., et al. (2009). FGF21 induces PGC-lalpha and regulates carbohydrate and fatty acid metabolism during the adaptive starvation response. Proc. Natl. Acad. Sci. U. S. A. 106, 10853-10858. doi: 10.1073/pnas.0904187106

Ribas, F., Villarroya, J., Hondares, E., Giralt, M., and Villarroya, F. (2014). FGF21 expression and release in muscle cells: involvement of MyoD and regulation by mitochondria-driven signaling. Biochem. J. 463, 191-199. doi: 10.1042/BJ20140403

Rodriguez-Nuevo, A., Diaz-Ramos, A., Noguera, E., Diaz-Saez, F., Duran, X., Munoz, J. P., et al. (2018). Mitochondrial DNA and TLR9 drive muscle inflammation upon Opal deficiency. EMBO J. 37:e96553. doi: 10.15252/ embj.201796553

Romanello, V., Scalabrin, M., Albiero, M., Blaauw, B., Scorrano, L., and Sandri, M. (2019). Inhibition of the fission machinery mitigates OPAl impairment in adult skeletal muscles. Cell 8:597. doi: 10.3390/cells8060597

Rosenberg, A. S., Puig, M., Nagaraju, K., Hoffman, E. P., Villalta, S. A., Rao, V. A., et al. (2015). Immune-mediated pathology in Duchenne muscular dystrophy. Sci. Transl. Med. 7:299rv294. doi: 10.1126/scitranslmed.aaa7322

Sabaratnam, R., Pedersen, A. J. T., Kristensen, J. M., Handberg, A., Wojtaszewski, J. F. P., and Hojlund, K. (2018). Intact regulation of muscle expression and circulating levels of myokines in response to exercise in patients with type 2 diabetes. Physiol. Rep. 6:e13723. doi: 10.14814/phy2.13723

Salminen, A., Kaarniranta, K., and Kauppinen, A. (2017a). Integrated stress response stimulates FGF21 expression: systemic enhancer of longevity. Cell. Signal. 40, 10-21. doi: 10.1016/j.cellsig.2017.08.009

Salminen, A., Kaarniranta, K., and Kauppinen, A. (2017b). Regulation of longevity by FGF21: interaction between energy metabolism and stress responses. Ageing Res. Rev. 37, 79-93. doi: 10.1016/j.arr.2017.05.004

Salminen, A., Kauppinen, A., and Kaarniranta, K. (2017c). FGF21 activates AMPK signaling: impact on metabolic regulation and the aging process. $J$. Mol. Med. (Berl) 95, 123-131. doi: 10.1007/s00109-016-1477-1

Schiaffino, S., and Reggiani, C. (2011). Fiber types in mammalian skeletal muscles. Physiol. Rev. 91, 1447-1531. doi: 10.1152/physrev.00031.2010

Schmidt, D. R., Holmstrom, S. R., Fon Tacer, K., Bookout, A. L., Kliewer, S. A., and Mangelsdorf, D. J. (2010). Regulation of bile acid synthesis by fat-soluble vitamins A and D. J. Biol. Chem. 285, 14486-14494. doi: 10.1074/jbc. M110.116004

Shabkhiz, F., Khalafi, M., Rosenkranz, S., Karimi, P., and Moghadami, K. (2020). Resistance training attenuates circulating FGF-21 and myostatin and improves insulin resistance in elderly men with and without type 2 diabetes mellitus: a randomised controlled clinical trial. Eur. J. Sport Sci. 1-10. doi: 10.1080/ 17461391.2020.1762755 [Epub ahead of print]

Sherrier, M., and Li, H. (2019). The impact of keto-adaptation on exercise performance and the role of metabolic-regulating cytokines. Am. J. Clin. Nutr. 110, 562-573. doi: 10.1093/ajcn/nqz145

So, W. Y., Cheng, Q., Chen, L., Evans-Molina, C., Xu, A., Lam, K. S., et al. (2013). High glucose represses beta-klotho expression and impairs fibroblast growth factor 21 action in mouse pancreatic islets: involvement of peroxisome proliferator-activated receptor gamma signaling. Diabetes 62, 3751-3759. doi: $10.2337 / \mathrm{db} 13-0645$

Sonoda, J., Chen, M. Z., and Baruch, A. (2017). FGF21-receptor agonists: an emerging therapeutic class for obesity-related diseases. Horm. Mol. Biol. Clin. Investig. 30. doi: 10.1515/hmbci-2017-0002

Staiger, H., Keuper, M., Berti, L., Hrabe de Angelis, M., and Haring, H. U. (2017). Fibroblast growth factor 21-metabolic role in mice and men. Endocr. Rev. 38, 468-488. doi: 10.1210/er.2017-00016

Steele, H. E., Horvath, R., and Taylor, R. W. (2016). The swinging pendulum of biomarkers in mitochondrial disease: the role of FGF21. Neurology 87, 2286-2287. doi: 10.1212/wnl.0000000000003383

Struik, D., Dommerholt, M. B., and Jonker, J. W. (2019). Fibroblast growth factors in control of lipid metabolism: from biological function to clinical application. Curr. Opin. Lipidol. 30, 235-243. doi: 10.1097/MOL.00000 00000000599

Suomalainen, A., Elo, J. M., Pietilainen, K. H., Hakonen, A. H., Sevastianova, K., Korpela, M., et al. (2011). FGF-21 as a biomarker for muscle-manifesting mitochondrial respiratory chain deficiencies: a diagnostic study. Lancet Neurol. 10, 806-818. doi: 10.1016/S1474-4422(11)70155-7

Suzuki, M., Uehara, Y., Motomura-Matsuzaka, K., Oki, J., Koyama, Y., Kimura, M., et al. (2008). betaKlotho is required for fibroblast growth factor (FGF) 21 signaling through FGF receptor (FGFR) $1 \mathrm{c}$ and FGFR3c. Mol. Endocrinol. 22, 1006-1014. doi: 10.1210/me.2007-0313

Talbot, J., and Maves, L. (2016). Skeletal muscle fiber type: using insights from muscle developmental biology to dissect targets for susceptibility and resistance to muscle disease. Wiley Interdiscip. Rev. Dev. Biol. 5, 518-534. doi: 10.1002/ wdev.230

Talukdar, S., Zhou, Y., Li, D., Rossulek, M., Dong, J., Somayaji, V., et al. (2016). A long-acting FGF21 molecule, PF-05231023, decreases body weight and improves lipid profile in non-human primates and type 2 diabetic subjects. Cell Metab. 23, 427-440. doi: 10.1016/j.cmet.2016.02.001 
Taniguchi, H., Tanisawa, K., Sun, X., Kubo, T., and Higuchi, M. (2016). Endurance exercise reduces hepatic fat content and serum fibroblast growth factor 21 levels in elderly men. J. Clin. Endocrinol. Metab. 101, 191-198. doi: 10.1210/ jc.2015-3308

Tanimura, Y., Aoi, W., Takanami, Y., Kawai, Y., Mizushima, K., Naito, Y., et al. (2016). Acute exercise increases fibroblast growth factor 21 in metabolic organs and circulation. Physiol. Rep. 4:e12828. doi: 10.14814/phy2.12828

Tezze, C., Romanello, V., Desbats, M. A., Fadini, G. P., Albiero, M., Favaro, G., et al. (2017). Age-associated loss of OPA1 in muscle impacts muscle mass, metabolic homeostasis, systemic inflammation, and epithelial senescence. Cell Metab. 25, 1374-1389.e1376. doi: 10.1016/j.cmet.2017.04.021

Tezze, C., Romanello, V., and Sandri, M. (2019). FGF21 as modulator of metabolism in health and disease. Front. Physiol. 10:419. doi: 10.3389/ fphys.2019.00419

Timpani, C. A., Hayes, A., and Rybalka, E. (2015). Revisiting the dystrophinATP connection: how half a century of research still implicates mitochondrial dysfunction in Duchenne muscular dystrophy aetiology. Med. Hypotheses 85, 1021-1033. doi: 10.1016/j.mehy.2015.08.015

Tomiyama, K., Maeda, R., Urakawa, I., Yamazaki, Y., Tanaka, T., Ito, S., et al. (2010). Relevant use of Klotho in FGF19 subfamily signaling system in vivo. Proc. Natl. Acad. Sci. U. S. A. 107, 1666-1671. doi: 10.1073/pnas.0913986107

Tsai, S., Sitzmann, J. M., Dastidar, S. G., Rodriguez, A. A., Vu, S. L., McDonald, C. E., et al. (2015). Muscle-specific 4E-BP1 signaling activation improves metabolic parameters during aging and obesity. J. Clin. Invest. 125, 2952-2964. doi: $10.1172 /$ jci77361

Tyynismaa, H., Carroll, C. J., Raimundo, N., Ahola-Erkkila, S., Wenz, T., Ruhanen, H., et al. (2010). Mitochondrial myopathy induces a starvationlike response. Hum. Mol. Genet. 19, 3948-3958. doi: 10.1093/hmg/ddq310

Vandanmagsar, B., Warfel, J. D., Wicks, S. E., Ghosh, S., Salbaum, J. M., Burk, D., et al. (2016). Impaired mitochondrial fat oxidation induces FGF21 in muscle. Cell Rep. 15, 1686-1699. doi: 10.1016/j.celrep.2016.04.057

Vinales, K. L., Begaye, B., Bogardus, C., Walter, M., Krakoff, J., and Piaggi, P. (2019). FGF21 is a hormonal mediator of the human "thrifty" metabolic phenotype. Diabetes 68, 318-323. doi: 10.2337/db18-0696

Wang, Y., and Pessin, J. E. (2013). Mechanisms for fiber-type specificity of skeletal muscle atrophy. Curr. Opin. Clin. Nutr. Metab. Care 16, 243-250. doi: $10.1097 /$ MCO.0b013e328360272d

Wang, H., Qiang, L., and Farmer, S. R. (2008). Identification of a domain within peroxisome proliferator-activated receptor gamma regulating expression of a group of genes containing fibroblast growth factor 21 that are selectively repressed by SIRT1 in adipocytes. Mol. Cell. Biol. 28, 188-200. doi: 10.1128/ MCB.00992-07

Wei, W., Dutchak, P. A., Wang, X., Ding, X., Wang, X., Bookout, A. L., et al. (2012). Fibroblast growth factor 21 promotes bone loss by potentiating the effects of peroxisome proliferator-activated receptor gamma. Proc. Natl. Acad. Sci. U. S. A. 109, 3143-3148. doi: 10.1073/pnas.1200797109

Wu, S., Grunwald, T., Kharitonenkov, A., Dam, J., Jockers, R., and De Luca, F. (2013). Increased expression of fibroblast growth factor 21 (FGF21) during chronic undernutrition causes growth hormone insensitivity in chondrocytes by inducing leptin receptor overlapping transcript (LEPROT) and leptin receptor overlapping transcript-like 1 (LEPROTL1) expression. J. Biol. Chem. 288, 27375-27383. doi: 10.1074/jbc.M113.462218

Wu, S., Levenson, A., Kharitonenkov, A., and De Luca, F. (2012). Fibroblast growth factor 21 (FGF21) inhibits chondrocyte function and growth hormone action directly at the growth plate. J. Biol. Chem. 287, 26060-26067. doi: 10.1074/jbc.M112.343707

Xiong, Y., Chen, Y., Liu, Y., and Zhang, B. (2020). Moderate-intensity continuous training improves FGF21 and KLB expression in obese mice. Biochemistry (Mosc) 85, 938-946. doi: 10.1134/S000629792008009X

Yan, Z., Okutsu, M., Akhtar, Y. N., and Lira, V. A. (2011). Regulation of exercise-induced fiber type transformation, mitochondrial biogenesis, and angiogenesis in skeletal muscle. J. Appl. Physiol. (1985) 110, 264-274. doi: 10.1152/japplphysiol.00993.2010

Yang, S. J., Hong, H. C., Choi, H. Y., Yoo, H. J., Cho, G. J., Hwang, T. G., et al. (2011). Effects of a three-month combined exercise programme on fibroblast growth factor 21 and fetuin-a levels and arterial stiffness in obese women. Clin. Endocrinol. 75, 464-469. doi: 10.1111/j.1365-2265.2011.04078.x

Youm, Y. H., Horvath, T. L., Mangelsdorf, D. J., Kliewer, S. A., and Dixit, V. D. (2016). Prolongevity hormone FGF21 protects against immune senescence by delaying age-related thymic involution. Proc. Natl. Acad. Sci. U. S. A. 113, 1026-1031. doi: 10.1073/pnas.1514511113

Yu, H., Xia, F., Lam, K. S., Wang, Y., Bao, Y., Zhang, J., et al. (2011). Circadian rhythm of circulating fibroblast growth factor 21 is related to diurnal changes in fatty acids in humans. Clin. Chem. 57, 691-700. doi: 10.1373/clinchem. 2010.155184

Zhang, Y., Xie, Y., Berglund, E. D., Coate, K. C., He, T. T., Katafuchi, T., et al. (2012). The starvation hormone, fibroblast growth factor-21, extends lifespan in mice. eLife 1:e00065. doi: 10.7554/eLife.00065

Zhang, X., Yeung, D. C., Karpisek, M., Stejskal, D., Zhou, Z. G., Liu, F., et al. (2008). Serum FGF21 levels are increased in obesity and are independently associated with the metabolic syndrome in humans. Diabetes 57, 1246-1253. doi: $10.2337 / \mathrm{db} 07-1476$

Zhou, S., Qian, B., Wang, L., Zhang, C., Hogan, M. V., and Li, H. (2018). Altered bone-regulating myokine expression in skeletal muscle of Duchenne muscular dystrophy mouse models. Muscle Nerve 58, 573-582. doi: 10.1002/ mus.26195

Conflict of Interest: The authors declare that the research was conducted in the absence of any commercial or financial relationships that could be construed as a potential conflict of interest.

Copyright (c) 2021 Sun, Sherrier and Li. This is an open-access article distributed under the terms of the Creative Commons Attribution License (CC BY). The use, distribution or reproduction in other forums is permitted, provided the original author(s) and the copyright owner(s) are credited and that the original publication in this journal is cited, in accordance with accepted academic practice. No use, distribution or reproduction is permitted which does not comply with these terms. 